\title{
Huanglian-Jie-Du-Tang Extract Protects against Chronic Brain Injury after Focal Cerebral Ischemia via Hypoxia-Inducible-Factor-1 $\alpha$ - Regulated Vascular Endothelial Growth Factor Signaling in Mice
}

\author{
Yilu Ye, ${ }^{a}$ Chunyan Huang, ${ }^{a, b}$ Lili Jiang, ${ }^{a, b}$ Xiangdi Shen, ${ }^{a}$ Shanyong Zhu, ${ }^{a}$ Yan Rao, ${ }^{a}$ \\ Jue Wang, ${ }^{a}$ and Qi Zhang*,a \\ ${ }^{a}$ Department of Pharmacology, Zhejiang Medical College; 481 Binwen Road, Hangzhou 310053, China: and ${ }^{b}$ School \\ of Pharmacy, Wenzhou Medical College; Chashan Campus, Wenzhou 325035, China. \\ Received September 12, 2011; accepted December 3, 2011; published online December 16, 2011
}

Huanglian-Jie-Du-Tang (HJDT) is a traditional Chinese herbal formula which is widely used clinically. In this study, we investigated the effects of an aqueous (HJDTaq) and an ethanolic (HJDTet) extract of HJDT on chronic brain injury after focal cerebral ischemia in mice. The ischemia was induced by occlusion of the right middle cerebral artery for $30 \mathrm{~min}$. HJDTaq $(4 \mathrm{~g} / \mathrm{kg})$ and HJDTet $(200,400,800 \mathrm{mg} / \mathrm{kg})$ were orally administered for $21 \mathrm{~d}$ from day 7 before ischemia to day 14 after ischemia. The survival rate decreased to less than $50 \%$ at $35 \mathrm{~d}$ after ischemia. HJDTet at $400 \mathrm{mg} / \mathrm{kg}$ increased the survival rate. HJDTaq $(4 \mathrm{~g} / \mathrm{kg})$ and HJDTet $(400,800 \mathrm{mg} / \mathrm{kg})$ significantly attenuated the neurological dysfunction, brain atrophy and infarct volume after ischemia. There were few cells positive for CD31, hypoxia-inducible-factor-1 $\alpha(\mathrm{HIF}-1 \alpha)$, vascular endothelial growth factor (VEGF) and Flk-1 in the sham control. After ischemia, the number increased. HJDTaq $(4 \mathrm{~g} / \mathrm{kg})$ and HJDTet $(400$ or $800 \mathrm{mg} / \mathrm{kg})$ further increased the numbers of CD31, HIF-1 $\alpha$, VEGF and Flk-1-positive cells in the ischemic hemisphere. We conclude that HJDTaq and HJDTet have neuroprotective effects on chronic brain injury after focal cerebral ischemia and lead to accelerated angiogenesis by HIF-1 $\alpha$ regulated VEGF signaling.

Key words aqueous extract; ethanolic extract; cerebral ischemia; angiogenesis; mouse

Cerebral ischemia and stroke are the leading causes of adult disability and remain the third most common causes of death in industrialized nations. ${ }^{1)}$ Ischemic brain injury can be separated into 3 sequential phases: acute (minutes to hours), subacute (hours to days), and chronic (days to months). ${ }^{2}$ Neurogenesis, gliosis/glial scar formation and angiogenesis occur (brain remodeling) in the chronic phase after ischemia or other brain injuries. ${ }^{3)}$ Among these changes, angiogenesis increases cerebral blood flow, and improves brain tissue recovery as well as functional outcome. ${ }^{4)}$

Huanglian-Jie-Du-Tang (HJDT) is a traditional Chinese herbal formula composed of four herbs: Rhizoma Coptidis, Radix Scutellariae, Cortex Phellodendri and Fructus Gardeniae. It is widely used for alleviating the symptoms of liver injury, ${ }^{5,6}$ gastrointestinal disorders, ${ }^{7)}$ inflammation, ${ }^{8,9}$ cardiovascular diseases, ${ }^{10)}$ and multiple myeloma. ${ }^{11)}$ Evidence shows that HJDT or its ingredient also protect against acute ischemic brain injury. ${ }^{12-15)}$ We showed previously that the aqueous extract of HJDT (HJDTaq) has neuroprotective effects on chronic brain injury after focal cerebral ischemia in mice. ${ }^{16)}$ HJDT inhibits cardiac remodeling in a rat model of metabolic syndrome by reducing myocardial collagen deposition. $^{17)}$

Furthermore, the original Chinese patent medicine is a poorly-defined and variable herbal mixture that is usually prescribed in large doses. Definition of the active ingredients improves the safety, effectiveness and quality of such medicines. ${ }^{18)}$ So, as the next step to identify the active components, the aqueous extract of HJDT (HJDTaq) was further subjected to D101 resin column chromatography, and eluted ethanol to give an ethanol-soluble (HJDTet) fraction.

Whether HJDTet has protective effects on chronic brain injury after focal cerebral ischemia and influences brain remodeling have not been reported. Thus, we investigated the neuroprotective effects and the underlying mechanisms of action of HJDTet on chronic brain injury after focal cerebral ischemia in mice.

\section{MATERIALS AND METHODS}

Samples and Preparation of HJDTet Rhizoma Coptidis, Radix Scutellariae, Cortex Phellodendri and Fructus Gardeniae were purchased from Eastern China Medical Corp., Zhejiang Province, China. HJDT is composed of Rhizoma Coptidis, Radix Scutellariae, Cortex Phellodendri, and Fructus Gardeniae at the ratio of $3: 3: 2: 3$. The materials $(5.5 \mathrm{~kg})$ were decocted three times under reflux. The first aqueous extract was concentrated in a rotary evaporator under reduced pressure, and then lyophilized to give $962.5 \mathrm{~g}$ of aqueous extract (HJDTaq, yield $17.5 \%(\mathrm{w} / \mathrm{w}))$. The HJDTaq $(600 \mathrm{~g})$ was subjected to D101 resin column chromatography, washed with $\mathrm{ddH}_{2} \mathrm{O}$, and eluted with ethyl alcohol to give $254.7 \mathrm{~g}$ of ethanolic extract (HJDTet; yield 7.43\% (w/w)).

Then HPLC was carried out on a Waters 600E instrument equipped with a Waters 2996 PDA detector (Lumtech, Germany). A Symmetry ${ }^{\circledR}$ C18 column $(250 \mathrm{~mm} \times 4.6 \mathrm{~mm}$ i.d., particle size $5 \mu \mathrm{m}$ ) was used for separations. HPLC conditions were as follows: eluent A, acetonitrile; eluent B, $0.05 \%$ potassium dihydrogen phosphate- $0.05 \%$ triethanolamine-water ( $\mathrm{pH} 3.0$ adjusted by phosphoric acid); gradient, 0 min (A-B, $14: 86) \rightarrow 12$ min $(\mathrm{A}-\mathrm{B}, 25: 75) \rightarrow 27$ min $(\mathrm{A}-\mathrm{B}, 30: 70) \rightarrow 28 \mathrm{~min}$ (A-B, 14:86), and then equilibrated with A-B (14:86) for $12 \mathrm{~min}$ at a flow of $0.8 \mathrm{~mL} / \mathrm{min}$. Peaks were assigned by comparing their retention times with that of each reference compound eluted in parallel with the same mobile phase and by spiking the sample with reference compounds. The contents of the analytics were determined from the corresponding calibration curves. Reports have suggested that berberine, baicalin 


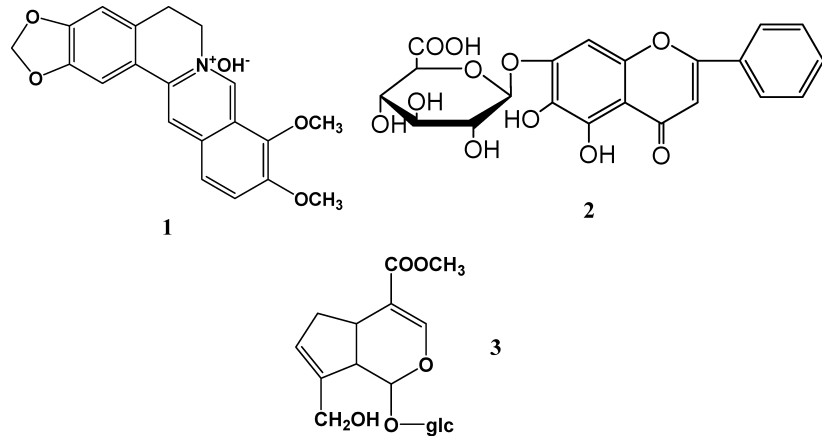

Fig. 1. Structures of Berberine (1), Baicalin (2), and Geniposide (3)

and geniposide protect against acute cerebral ischemia. ${ }^{19-21)}$ Therefore, these three compounds (Fig. 1) were used for quantitative analysis of HJDTet. The content of berberine, baicalin, and geniposide in HJDTet was found to be $1.44 \%, 3.35 \%$, and $2.12 \%$, respectively. These may be main components of HJDT to protect against the chronic cerebral ischemia.

Animals and Drug Treatment Male Kunming mice, weighing 22-24g, were purchased from Shanghai Slyke Laboratory Animal Corp. (Certificate No. SCXK 2007-0005, Shanghai, China) and acclimatized for 1 week before use. All experiments were carried out in accordance with the National Institute of Health Guide for the Care and Use of Laboratory Animals. The animals were housed at a controlled temperature $\left(22 \pm 1^{\circ} \mathrm{C}\right)$ and humidity $50 \pm 10 \%$, under a $12 / 12 \mathrm{~h} \mathrm{light/}$ dark cycle. They were allowed free access to food and water.

The mice were divided into 6 groups $(n=163)$, each consisting of $25-31$ mice. HJDTet $(200 \mathrm{mg} / \mathrm{kg}, n=25 ; 400 \mathrm{mg} / \mathrm{kg}$, $n=27 ; 800 \mathrm{mg} / \mathrm{kg}, n=28)$ and HJDTaq $(4 \mathrm{~g} / \mathrm{kg}, n=25)$ were administered orally once a day for $21 \mathrm{~d}$ from day 7 before ischemia until day 14 after ischemia. The sham $(n=27)$ and ischemia $(n=31)$ controls were treated orally with $0.5 \%$ carboxymethyl cellulose solution.

Transient Focal Cerebral Ischemia Transient focal cerebral ischemia was induced by middle cerebral artery occlusion (MCAO) as described by Mao et al. ${ }^{22)}$ After anesthesia with chloral hydrate $(400 \mathrm{mg} / \mathrm{kg})$, a $6-0$ nylon monofilament suture, blunted at the tip and coated with $1 \%$ poly-L-lysine, was inserted into the internal carotid artery, and advanced approximately $10 \mathrm{~mm}$ distal to the carotid bifurcation to occlude the origin of the MCA. The suture was carefully withdrawn $30 \mathrm{~min}$ after MCAO. In sham-operated mice, the same procedure was done with the exception of inserting the intraluminal filament. The mice with intracranial haemorrhage were excluded.

Neurological Deficit Score The neurological deficit score was evaluated as described by Bederson et al. ${ }^{23)}$ : 0 , no deficit; 1, failure to fully extend left forepaw; 2 , circling to the left; 3 , falling to the left; 4 , no spontaneous walking with a depressed level of consciousness. Then, mice were scored on days 1, 3, and 7 in the first week after $\mathrm{MCAO}$, and once every week thereafter.

Inclined Board Test An inclined board test was performed to assess balance and coordination based on modifications of a method described by Yonemori et al. ${ }^{24)}$ Mice were placed on a board $(25 \mathrm{~cm} \times 15 \mathrm{~cm})$ covered by copper wire mesh $(0.2 \mathrm{~mm})$ after MCAO. Once the mouse had stabi- lized, the board was inclined from horizontal to vertical. The holding angle at which the animal fell from the board was recorded. The test was repeated three times and the average angle was calculated.

Histopathological Examination Mice were anesthetized after neurological evaluation at day 35 after MCAO and perfused transcardially with $4 \%$ paraformaldehyde after preflushing with ice-cold saline. Brains were removed, fixed with the same fixative for $24 \mathrm{~h}$, and then stored in $30 \%$ sucrose in $0.1 \mathrm{M}$ phosphate buffered saline at $4^{\circ} \mathrm{C}$ for $1-2 \mathrm{~d}$. The brains were cut into 10 or $20-\mu \mathrm{m}$ coronal sections on a cryomicrotome (CM1900, Leica, Germany) $-2.0 \mathrm{~mm}$ from bregma. The $20-\mu \mathrm{m}$ sections from the central region of the ischemic infarction were photographed by a digital camera (FinePix S602 Zoom, Fuji Film, Japan). The infarct volume was measured using an image analyzer (MedBrain-2, Zhejiang University, Hangzhou, China) in sections stained with $1 \%$ toluidine blue (Sigma Chemical Co., St. Louis, MO, U.S.A.). Then, the 10$\mu \mathrm{m}$ sections were used for histopathological examination and counting neuron densities in the hippocampal CA1 region, temporal cortex and striatum. The numbers of healthy-looking neurons (large cells with a pyramidal shape) in layers III-IV of the temporoparietal cortex, hippocampal CA1 region and striatum were counted in sections stained with $1 \%$ toluidine blue.

Immunohistochemical Evaluation To assess post-ischemic angiogenesis, immunohistochemical procedures were performed using the polyclonal rabbit antibodies against CD31 (a marker of microvessels), hypoxia-inducible-factor-1 $\alpha$ (HIF$1 \alpha$ ), vascular endothelial growth factor (VEGF) and Flk-1. The $10-\mu \mathrm{m}$ sections were treated with $0.3 \% \mathrm{H}_{2} \mathrm{O}_{2}$ in methanol for $30 \mathrm{~min}$, hydrated gradually to distilled water, and incubated for $2 \mathrm{~h}$ with $5 \%$ goat serum to block nonspecific immune reactions. Sections were then incubated overnight at $4{ }^{\circ} \mathrm{C}$ with polyclonal rabbit anti-CD31, -HIF-1 $\alpha$, -VEGF and -Flk-1 antibodies $(1: 200$, Wuhan Boster Biological Engineering Co., Wuhan, China). The next day, after washing, the sections were incubated with biotinylated goat anti-rabbit immunoglobulin $\mathrm{G}$ ( $1: 200$, Wuhan Boster) for $2 \mathrm{~h}$ followed by incubation with avidin-biotin-peroxidase complex $(1: 200$, Wuhan Boster) for $2 \mathrm{~h}$. Finally, the sections were exposed for $0.5-2 \mathrm{~min}$ to $0.01 \%$ 3,3'-diaminobenzidine (Wuhan Boster). Normal goat serum was used instead of the primary antibody in the control sections. Positive cells were counted in the ischemic hemisphere.

Statistical Analysis The data are expressed as mean \pm standard error (S.E.). Survival curves were constructed according to the Kaplan-Meier method. Differences in survival rates among groups were examined by the log rank test. Others were performed using one-way analysis of variance or the non-parametric Kruskal-Wallis test if the data had a skewed distribution (neurological deficit score) and the Dunnett $t$-test for neuron density compared with the non-ischemic hemisphere. $p<0.05$ was considered to be statistically significant.

\section{RESULTS}

HJDTet Increased the Survival Rate of Mice Compared with the ischemia control, HJDTet enhanced the survival rates after ischemia at $400 \mathrm{mg} / \mathrm{kg}$. Although HJDTaq and HJDTet $(200,800 \mathrm{mg} / \mathrm{kg})$ also improved the survival rates after isch- 
emia, there were no significant differences between these groups and the ischemia control (Fig. 2).

HJDTet Reduced the Neurological Deficit Score The neurological deficit score gradually increased and reached the maximum at $24 \mathrm{~h}$ after ischemia; thereafter it decreased, and remained constant until day 35 (Table 1). Treatment with HJDTet at 400 and $800 \mathrm{mg} / \mathrm{kg}$, but not $200 \mathrm{mg} / \mathrm{kg}$, reduced the score from days 14 to 35 . HJDTaq also reduced the score from days 14 to 35 .

HJDTet Increased the Performance on the Inclined Board Test In the inclined board test, the performance of sham-operated mice remained constant over $35 \mathrm{~d}$ after operation. After ischemia, the performance decreased from days 1 to 35 and reached a minimum at $24 \mathrm{~h}$ (Table 2). Treatment with HJDTet increased the performance at days 14 and 28 at 200 and $400 \mathrm{mg} / \mathrm{kg}$ and at days 1 and 14 at $800 \mathrm{mg} / \mathrm{kg}$. The performance in HJDTaq-treated ischemic mice was also increased at day 14 .

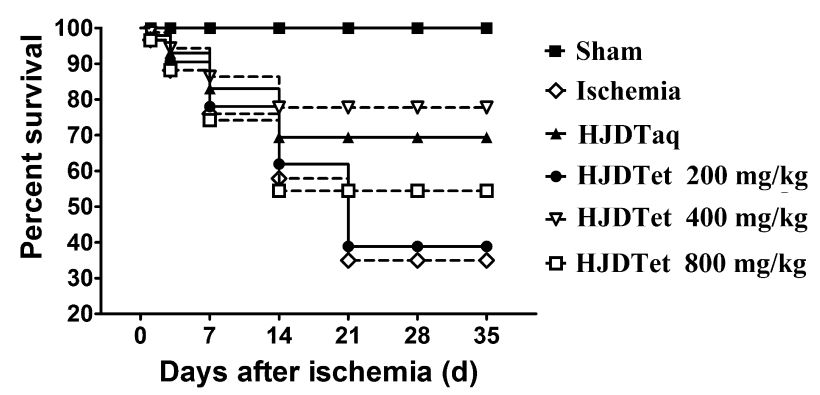

Fig. 2. Survival Rates of Mice Treated with HJDTaq and HJDTet after Ischemia

Compared with ischemic mice, those treated with HJDTet at $400 \mathrm{mg} / \mathrm{kg}$ had a higher survival rate $(p<0.05)$. Curves were constructed according to the KaplanMeier method. Differences of survival rates among groups were determined by the $\log$ rank test. HJDTaq, aqueous extract of Huanglian-Jie-Du-Tang; HJDTet, ethanolic extract of Huanglian-Jie-Du-Tang.
HJDTet Reduced the Infarct Volume At day 35 after ischemia, the ischemic hemisphere was clearly atrophic on gross examination (Fig. 3A) and in the sections stained with toluidine blue (Fig. 3B). The infarct volume at day 35 after ischemia was increased. Treatment with HJDTaq and HJDTet at 400 and $800 \mathrm{mg} / \mathrm{kg}$, but not $200 \mathrm{mg} / \mathrm{kg}$, markedly reduced the infarct volume compared to the ischemia control (Fig. 3C).

HJDTet Increased the Neuron Density in Hippocampal CA1 Region, Cortex and Striatum The neuron density significantly decreased at day 35 after ischemia in the hippocampal CA1 region, cortex and striatum of the ischemic hemisphere. Treatment with HJDTaq and HJDTet at $800 \mathrm{mg} /$ $\mathrm{kg}$ increased the neuron density in hippocampal CA1 region, cortex and striatum (Fig. 4). Treatment with HJDTet at $400 \mathrm{mg} / \mathrm{kg}$ increased the neuron density of cortex only, but not the hippocampal CA1 region and striatum.

HJDTet Increased the Numbers of CD31-, HIF-1 $\alpha$-, VEGF- and Flk-1-Positive Cells There were few CD31-, HIF-1 $\alpha$-, VEGF- and Flk-1 positive cells in the sham control. After ischemia, the numbers of CD31- and HIF-1 $\alpha$-positive cells increased. Treatment with HJDTet at 400 and $800 \mathrm{mg} / \mathrm{kg}$ further increased the CD31- and HIF-1 $\alpha$-positive cell numbers (Figs. 5A, B). Increased VEGF- and Flk-positive cell numbers were found in the ischemic hemisphere of the ischemia control, but the difference was not significant. Treatment with HJDTaq $(4 \mathrm{~g} / \mathrm{kg})$ and HJDTet $(200,400,800 \mathrm{mg} / \mathrm{kg})$ increased the number of VEGF-positive cells over sham control, but only the $800 \mathrm{mg} / \mathrm{kg}$ HJDTet treatment increased the number over ischemia control (Fig. 5C). The number of cells expressing Flk-1, a VEGF receptor, was increased after treatment with HJDTaq and HJDTet $(400,800 \mathrm{mg} / \mathrm{kg})$ relative to sham control. Also, the number of Flk-1-positive cells was increased by HJDTaq and HJDTet $(800 \mathrm{mg} / \mathrm{kg})$ relative to ischemia control (Fig. 5D).
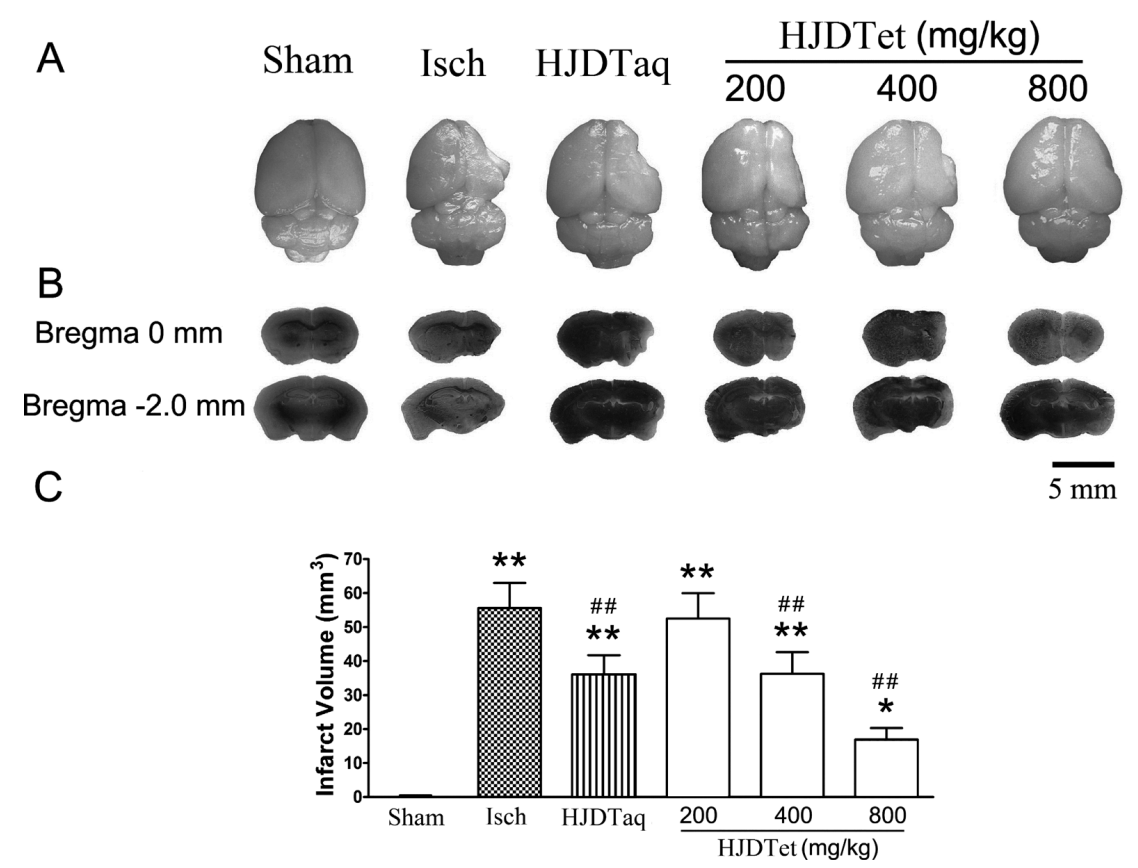

Fig. 3. Effects of HJDTaq and HJDTet on Infarct Volume at Day 35 after Focal Cerebral Ischemia in Mice

Mice were treated with HJDTet $(200,400,800 \mathrm{mg} / \mathrm{kg}$ ) or HJDTaq $(4 \mathrm{~g} / \mathrm{kg})$ for 21 consecutive days (initial dose at day 7 before ischemia). Data are expressed as mean \pm S.E. $(n=9-27) .{ }^{*} p<0.05$ or ${ }^{* *} p<0.01$ relative to sham control; ${ }^{\#} p<0.01$ relative to ischemia control. Isch, ischemia; HJDTaq, aqueous extract of Huanglian-JieDu-Tang; HJDTet, ethanolic extract of Huanglian-Jie-Du-Tang. Scale bar in B, $5 \mathrm{~mm}$. 

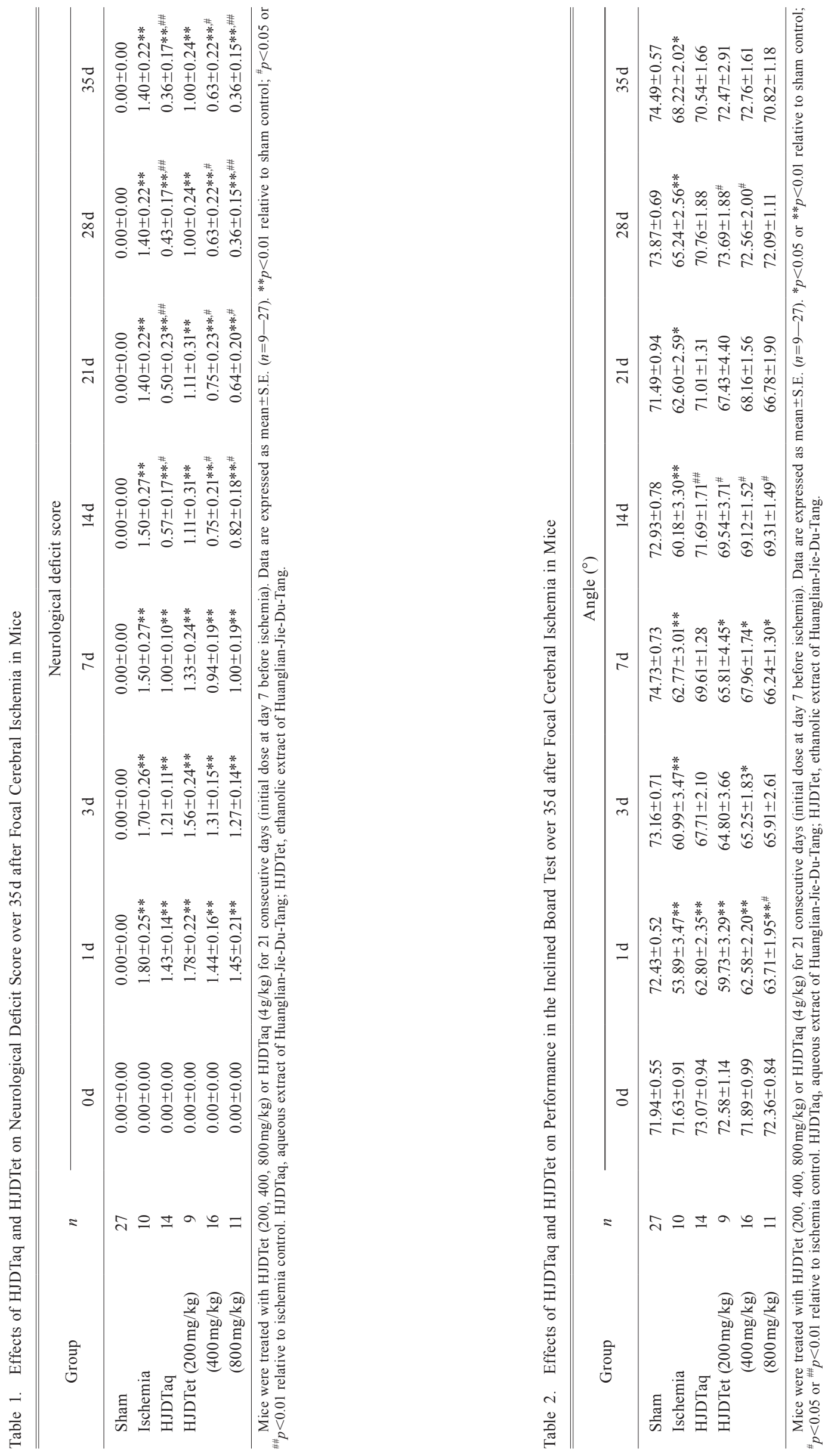
A Hippocampal CA1

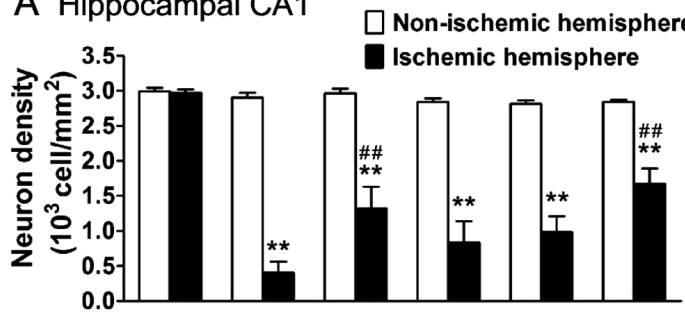

B Cortex

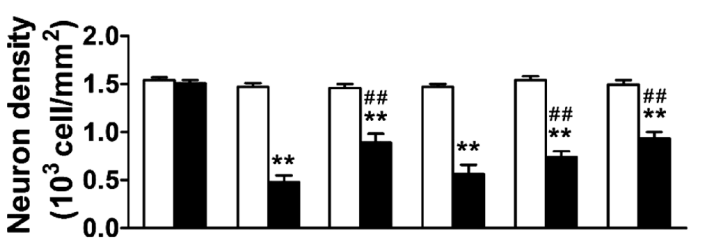

C Striatum

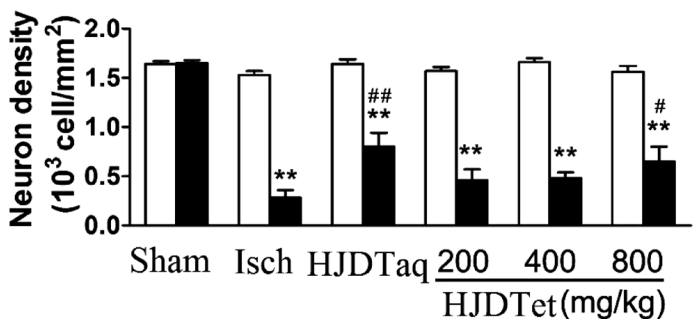

Fig. 4. Effects of HJDTaq and HJDTet on Neuron Density in Hippocampal CA1 Region, Cortex and Striatum at Day 35 after Focal Cerebral Ischemia in Mice

Data are expressed as mean \pm S.E. $(n=9-27) . * * p<0.01$ relative to non-ischemic hemisphere; ${ }^{\#} p<0.05$ or ${ }^{\#} p<0.01$ relative to ischemia control. Isch, ischemia HJDTaq, aqueous extract of Huanglian-Jie-Du-Tang; HJDTet, ethanolic extract of Huanglian-Jie-Du-Tang.

\section{DISCUSSION}

Here, we confirmed that HJDTet protects mice against chronic brain injury after focal cerebral ischemia. The results showed that HJDTet attenuated neurological dysfunction and reduced infarct volume as well as neuronal degeneration. The effective doses ranged from 400 to $800 \mathrm{mg} / \mathrm{kg}$. Furthermore, we found that HJDTet accelerated the angiogenesis surrounding the ischemic tissue as evidenced by increasing the number of CD31-positive cells, accompanied by increases of HIF-1 $\alpha$-, VEGF-, and Flk-1-positive cells.

More than half of the animals in the ischemia control group died within the 35-day observation period, likely due to the large cerebral infarct, the associated edema and intestinal tympanites, as previously reported. ${ }^{25,26)}$ HJDTaq and HJDTet reduced the death rate after ischemia during this period. Especially, HJDTet at $400 \mathrm{mg} / \mathrm{kg}$ enhanced the survival rate of mice after ischemia. However the survival rate was conversely reduced at $800 \mathrm{mg} / \mathrm{kg}$ HJDTet. The possible toxicity or the induced imbalance between endogenous regulatory mechanisms might relate to the failure in reducing death of ischemic mice after treatment of HJDTet at much larger doses (such as $800 \mathrm{mg} / \mathrm{kg})$.

Our studies showed that HJDTet exerted dose-dependent neuroprotective effects on chronic cerebral ischemia. The effective dose of HJDTet ranged from 400 to $800 \mathrm{mg} / \mathrm{kg}$, which is far lower than that reported for HJDTaq. ${ }^{8-10,12)}$ The lower effective dose of HJDTet indicated a more active prepara-
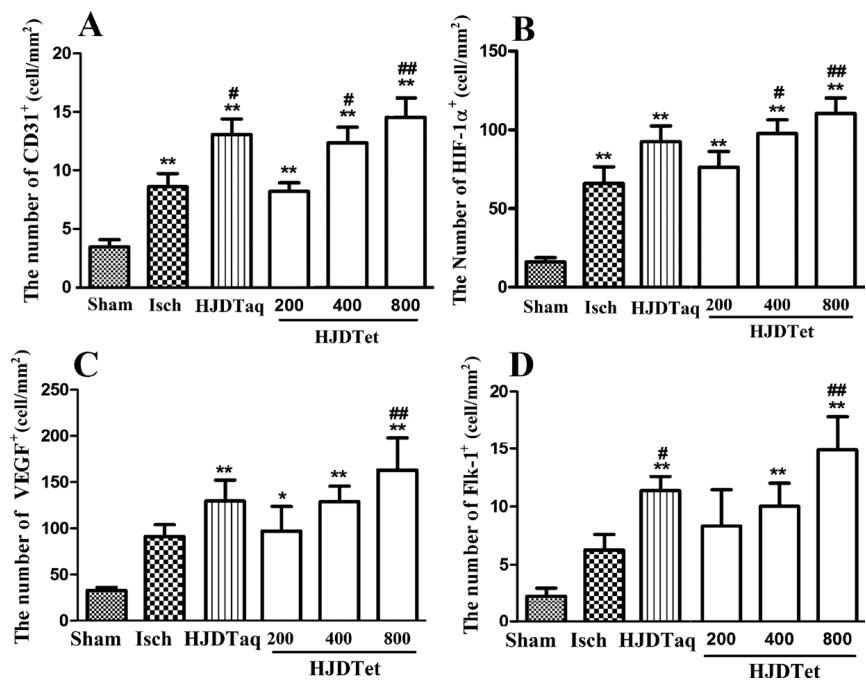

Fig. 5. Effects of HJDTaq and HJDTet on Numbers of CD31-, HIF-1 $\alpha-$, VEGF- and Flk-Positive Cells

Mice were treated with HJDTet $(200,400,800 \mathrm{mg} / \mathrm{kg})$ or HJDTaq $(4 \mathrm{~g} / \mathrm{kg})$ for 21 consecutive days (initial dose at day 7 before ischemia). Data are expressed as mean \pm S.E. $(n=9-27)$. ${ }^{*} p<0.05$ or $* * p<0.01$ relative to sham control; ${ }^{*} p<0.05$ or $\# p<0.01$ relative to ischemia control. Isch, ischemia; HJDTaq, aqueous extract of Huanglian-Jie-Du-Tang; HJDTet, ethanolic extract of Huanglian-Jie-Du-Tang.

tion, which was more effective and more potent. Meanwhile, we found the dose-response relationship is complex, i.e. for the survival rate, HJDTet showed a bell-type dose-response relation, while for other indicators it showed a typical doseresponse relation. Maybe it was due to these indicators were obtained from the survival mice whose severity of ischemic injury might be less than the died mice. The dose-dependent relation means the likelihood of deleterious side effects at larger doses. ${ }^{27)}$ In the clinic, drug administration is highly variable, ranging from single to multiple doses for up to 3 months. ${ }^{28)}$ To treat chronic cerebral ischemia, a single dose may not provide enough protection, so prolonged administration is necessary. If the dose-effect characteristics of drugs show a bell-type dose-response relation, prolonged administration of the larger doses of HJDTet can have deleterious side effects or reduce therapeutic efficacy. ${ }^{29)}$ Thus, the effective and safe doses should be investigated in clinical use of HJDTet.

Our new findings are that HJDTet modifies the postischemic brain remodeling as it accelerates angiogenesis in the boundary zone after $35 \mathrm{~d}$. HIF-1 is a well-known complex involved in the intracellular signaling in response to hypoxia and ischemia. HIF-1 is known to play a key role in the development of cancer and angiogenesis. ${ }^{30)}$ It consists of one HIF- $1 \alpha$ subunit and one HIF- $\beta$ subunit. Oxygen regulates the function, subcellular localization, and level of the HIF- $1 \alpha$ units, while HIF- $1 \beta$ is expressed continuously. ${ }^{31)}$ Our results showed increased numbers cells expressing HIF-1 $\alpha$ in the boundary of the ischemic region. However, Hwang et $a l .{ }^{19)}$ found that baicalein, an ingredient of HJDT, suppresses HIF- $1 \alpha$ protein accumulation and activation in BV2 murine microglial cells during cerebral ischemia. We cannot explain why the in vivo and in vitro findings are different, but the mechanisms involved in in vivo angiogenesis after ischemic brain injury may be more complex. 
Platelet endothelial cell adhesion molecule-1 (CD31/ PECAM-1) is a cell-cell adhesion molecule that is expressed on circulating platelets, on leukocytes, and at the intercellular junctions of vascular endothelial cells, where it mediates the interactions of these cells during the process of transendothelial cell migration, thrombosis, wound healing, and angiogenesis (in cancer, stroke and others). ${ }^{32-34)}$ VEGF promotes adult angiogenesis for re-establishment of blood flow following ischemic damage. ${ }^{35}$ ) Administration of exogenous VEGF following stroke results in reduced neuronal cell death, increased angiogenesis and increased vascular permeability. ${ }^{36-38)}$ In hypoxia, the transcription of VEGF is increasingly regulated by HIF-1 $\alpha$, one of the most potent regulators. ${ }^{39,40)}$ In conjunction with these findings, our studies showed that HJDTaq and HJDTet increased the expression of HIF- $1 \alpha$ and VEGF. We further showed that one of the VEGF receptors, Flk-1, was also increased in hypoxic/ischemic conditions, as previously reported. ${ }^{41-43)}$ These data suggest that the angiogenesis effects of HJDTaq and HJDTet may be related to the regulation of VEGF and its receptor.

In conclusion, the results of the present study show that HJDTet ameliorates chronic brain injury after focal cerebral ischemia in mice and leads to angiogenesis in the boundary ischemic region. HJDTet enhances the expression of HIF-1 $\alpha$ and its downstream targets, VEGF and Flk-1, ultimately leading to accelerated angiogenesis and ameliorated neurological outcome.

Acknowledgements This study was supported by Grants from the Scientific Foundation of Zhejiang Province Education Department (Y200909752) and the Scientific Foundation in TCM of Zhejiang Province (2011ZA018). The authors would like to thank Dr. I. C. Bruce for critically reading and revising this manuscript.

\section{REFERENCES}

1) Rosamond W, Flegal K, Furie K, Go A, Greenlund K, Haase N, Hailpern SM, Ho M, Howard V, Kissela B, Kittner S, Lloyd-Jones D, Mcdermott M, Meigs J, Moy C, Nichol G, O’donnell C, Roger V, Sorlie P, Steinberger J, Thom T, Wilson M, Hong Y. Heart disease and stroke statistics - update: a report from the American heart association statistics committee and stroke statistics subcommittee. Circulation, 117, 25-146 (2008).

2) Dirnagl U, Simon RP, Hallenbeck JM. Ischemic tolerance and endogenous neuroprotection. Trends Neurosci., 26, 248-254 (2003).

3) Bramlett HM, Dietrich WD. Pathophysiology of cerebral ischemia and brain trauma: similarities and differences. J. Cereb. Blood Flow Metab., 24, 133-150 (2004).

4) Krupinski J, Kaluza J, Kumar P, Kumar S, Wang JM. Role of angiogenesis in patients with cerebral ischemic stroke. Stroke, 25, 1794-1798 (1994).

5) Ohta $Y$, Kongo-Nishimura M, Hayashi $T$, Kishikawa $T$. Effect of oren-gedoku-to (huanglian-jie-du-tang) extract on disruption of hepatic antioxidant defense systems in rats treated with D-galactosamine. J. Ethnopharmacol., 94, 323-329 (2004).

6) Hsu YL, Kuo PL, Tzeng TF, Sung SC, Yen MH, Lin LT, Lin CC. Huang-lian-jie-du-tang, a traditional Chinese medicine prescription, induces cell-cycle arrest and apoptosis in human liver cancer cells in vitro and in vivo. J. Gastroenterol. Hepatol., 23, 290-299 (2008).

7) Ohta Y, Kobayashi T, Nishida K, Sasaki E, Ishiguro I. Preventive effect of Oren-gedoku-to (Huanglian-Jie-Du-Tang) extract on the development of stress-induced acute gastric mucosal lesions in rats. J. Ethnopharmacol., 67, 377-384 (1999).

8) Wang LM, Yamamoto T, Wang XX, Yang L, Koike Y, Shiba K, Mineshita S. Effects of oren-gedoku-to and unsei-in, Chinese traditional medicines, on interleukin- 8 and superoxide dismutase in rats. J. Pharm. Pharmacol., 49, 102-104 (1997).

9) Zeng H, Liu X, Dou S, Xu W, Li N, Liu X, Zhang W, Hu Z, Liu $R$. Huang-Lian-Jie-Du-Tang exerts anti-inflammatory effects in rats through inhibition of nitric oxide production and eicosanoid biosynthesis via the lipoxygenase pathway. J. Pharm. Pharmacol., 61, 1699-1707 (2009).

10) Sekiya N, Kainuma M, Hikiami $H$, Nakagawa $T$, Kouta $K$, Shibahara N, Shimada Y, Terasawa K. Oren-gedoku-to and Keishibukuryo-gan-ryo inhibit the progression of atherosclerosis in diet-induced hypercholesterolemic rabbits. Biol. Pharm. Bull., 28, 294-298 (2005).

11) Ma $Z$, Otsuyama $K$, Liu S, Abroun S, Ishikawa H, Tsuyama $N$, Obata M, Li FJ, Zheng X, Maki Y, Miyamoto K, Kawano MM. Baicalein, a component of Scutellaria radix from Huang-Lian-JieDu-Tang (HLJDT), leads to suppression of proliferation and induction of apoptosis in human myeloma cells. Blood, 105, 3312-3318 (2005).

12) Kabuto H, Asanuma M, Nishibayashi S, Iida M, Ogawa N. Chronic administration of Oren-gedoku-to (TJ15) inhibits ischemia-induced changes in brain indoleamine metabolism and muscarinic receptor binding in the Mongolian gerbil. Neurochem. Res., 22, 33-36 (1997).

13) $\mathrm{Xu} \mathrm{J}$, Murakami $\mathrm{Y}$, Matsumoto $\mathrm{K}$, Tohda M, Watanabe H, Zhang S, Yu Q, Shen J. Protective effect of Oren-gedoku-to (Huang-LianJie-Du-Tang) against impairment of learning and memory induced by transient cerebral ischemia in mice. J. Ethnopharmacol., 73, 405-413 (2000)

14) Kondo Y, Kondo F, Asanuma M, Tanaka K, Ogawa N. Protective effect of oren-gedoku-to against induction of neuronal death by transient cerebral ischemia in the $\mathrm{C} 57 \mathrm{BL} / 6$ mouse. Neurochem. Res., 25, 205-209 (2000).

15) Hwang YS, Shin CY, Huh Y, Ryu JH. Hwangryun-Hae-Dok-tang (Huanglian-Jie-Du-Tang) extract and its constituents reduce ischemia-reperfusion brain injury and neutrophil infiltration in rats. Life Sci., 71, 2105-2117 (2002).

16) Zhang Q, Ye YL, Yan YX, Zhang WP, Chu LS, Wei EQ, Yu YP. Protective effects of Huanglian-Jie-Du-Tang on chronic brain injury after focal cerebral ischemia in mice. Zhejiang Da Xue Xue Bao Yi Xue Ban, 38, 75-80 (2009).

17) Li X, Li C, Ji X, Song Z, Wang L, Zhang J, Zhang Y. Huang-LianJie-Du-Tang inhibits myocardial remodeling in a rat model of metabolic syndrome. J. Ethnopharmacol., 119, 259-265 (2008).

18) Shen ZB, Yin YQ, Tang CP, Yan CY, Chen C, Guo LB. Pharmacodynamic screening and simulation study of anti-hypoxia active fraction of xiangdan injection. J. Ethnopharmacol., 127, 103-107 (2010).

19) Hwang KY, Oh YT, Yoon H, Lee J, Kim H, Choe W, Kang I. Baicalein suppresses hypoxia-induced HIF-1alpha protein accumulation and activation through inhibition of reactive oxygen species and PI 3-kinase/Akt pathway in BV2 murine microglial cells. Neurosci. Lett., 444, 264-269 (2008).

20) Zhou XQ, Zeng XN, Kong H, Sun XL. Neuroprotective effects of berberine on stroke models in vitro and in vivo. Neurosci. Lett., 447, 31-36 (2008).

21) Zhang ZJ, Li P, Wang Z, Li PT, Zhang WS, Sun ZH, Zhang XJ, Wang YY. A comparative study on the individual and combined effects of baicalin and jasminoidin on focal cerebral ischemiareperfusion injury. Brain Res., 1123, 188-195 (2006).

22) Mao Y, Yang GY, Zhou LF, Stern JD, Betz AL. Focal cerebral ischemia in the mouse: description of a model and effects of permanent and temporary occlusion. Brain Res. Mol. Brain Res., 63, 366-370 (1999). 
23) Bederson JB, Pitts LH, Tsuji M, Nishimura MC, Davis RL, Bartkowski H. Rat middle cerebral artery occlusion: evaluation of the model and development of a neurologic examination. Stroke, 17, 472-476 (1986).

24) Yonemori F, Yamaguchi T, Yamada H, Tamura A. Evaluation of a motor deficit after chronic focal cerebral ischemia in rats. J. Cereb. Blood Flow Metab., 18, 1099 -1106 (1998).

25) Gibson CL, Murphy SP. Progesterone enhances functional recovery after middle cerebral artery occlusion in male mice. J. Cereb. Blood Flow Metab., 24, 805-813 (2004).

26) Ho WK, Wen HL, Lee CM. Tetramethylpyrazine for treatment of experimentally induced stroke in Mongolian gerbils. Stroke, 20, 96-99 (1989).

27) Ye YL, Shi WZ, Zhang WP, Wang ML, Zhou Y, Fang SH, Liu LY, Zhang Q, Yu YP, Wei EQ. Cilostazol, a phosphodiesterase 3 inhibitor, protects mice against acute and late ischemic brain injuries. Eur. J. Pharmacol., 557, 23-31 (2007).

28) Dyker AG, Lees KR. Duration of neuroprotective treatment for ischemic stroke. Stroke, 29, 535-542 (1998).

29) Cheng YD, Al-Khoury L, Zivin JA. Neuroprotection for ischemic stroke: two decades of success and failure. NeuroRx, 1, 36-45 (2004).

30) Chavez A, Miranda LF, Pichiule P, Chavez JC. Mitochondria and hypoxia-induced gene expression mediated by hypoxia-inducible factors. Ann. N. Y. Acad. Sci., 1147, 312-320 (2008).

31) Melillo G, Musso T, Sica A, Taylor LS, Cox GW, Varesio L. A hypoxia-responsive element mediates a novel pathway of activation of the inducible nitric oxide synthase promoter. J. Exp. Med., 182, 1683-1693 (1995).

32) Shyu WC, Lin SZ, Chiang MF, Su CY, Li H. Intracerebral peripheral blood stem cell (CD34+) implantation induces neuroplasticity by enhancing betal integrin-mediated angiogenesis in chronic stroke rats. J. Neurosci., 26, 3444-3453 (2006).

33) Crasta JA, Mishra S, Vallikad E. Ovarian serous carcinoma: relationship of p53 and bcl-2 with tumor angiogenesis and VEGF expression. Int. J. Gynecol. Pathol., 30, 521-526 (2011).
34) Spencer M, Unal R, Zhu B, Rasouli N, McGehee RE Jr, Peterson CA, Kern PA. Adipose tissue extracellular matrix and vascular abnormalities in obesity and insulin resistance. J. Clin. Endocrinol. Metab., 96, e1990-e1998 (2011).

35) Ferrara N. Vascular endothelial growth factor: basic science and clinical progress. Endocr. Rev., 25, 581-611 (2004).

36) Sun Y, Jin K, Xie L, Childs J, Mao XO, Logvinova A, Greenberg DA. VEGF-induced neuroprotection, neurogenesis, and angiogenesis after focal cerebral ischemia. J. Clin. Invest., 111, 1843-1851 (2003).

37) Greenberg DA, Jin K. From angiogenesis to neuropathology. Nature, 438, 954-959 (2005).

38) Zhang ZG, Zhang L, Jiang Q, Zhang R, Davies K, Powers C, Bruggen N, Chopp M. VEGF enhances angiogenesis and promotes blood-brain barrier leakage in the ischemic brain. J. Clin. Invest., 106, 829-838 (2000).

39) Harms KM, Li L, Cunningham LA. Murine neural stem/progenitor cells protect neurons against ischemia by HIF-1alpha-regulated VEGF signaling. PLOS ONE, 5, e9767 (2010).

40) Roitbak T, Li L, Cunningham LA. Neural stem/progenitor cells promote endothelial cell morphogenesis and protect endothelial cells against ischemia via HIF-1alpha-regulated VEGF signaling. $J$. Cereb. Blood Flow Metab., 28, 1530-1542 (2008).

41) $\mathrm{Mu} \mathrm{D}$, Jiang $X$, Sheldon RA, Fox CK, Hamrick SE, Vexler ZS, Ferriero DM. Regulation of hypoxia-inducible factor $1 \alpha$ and induction of vascular endothelial growth factor in a rat neonatal stroke model. Neurobiol. Dis., 14, 524-534 (2003).

42) Marti HJ, Bernaudin M, Bellail A, Schoch H, Euler M, Petit E, Risau W. Hypoxia-induced vascular endothelial growth factor expression precedes neovascularization after cerebral ischemia. Am. J. Pathol., 156, 965-976 (2000).

43) Choi DY, Baek YH, Huh JE, Ko JM, Woo H, Lee JD, Park DS. Stimulatory effect of cinnamomum cassia and cinnamic acid on angiogenesis through up-regulation of VEGF and Flk-1/KDR expression. Int. Immunopharmacol., 9, 959-967 (2009). 